\title{
O (RE)ENCONTRO DE ACHUTTI COM A VILA DIQUE
}

\author{
The (re)encounter of achutti with vila dique
}

Maíra Brum Rieck ${ }^{1}$

Priscila Chagas Oliveira $^{2}$

\section{http://dx.doi.org/10.52641/cadcaj.v7i1.656}

Resumo: Este artigo é um testemunho do reencontro de Luiz Eduardo Robinson Achutti e de suas fotografias com a Vila Dique. É também um testemunho do encontro de Achutti com o Museu das Memórias (In)Possíveis, que procurou o fotógrafo para justamente musealizar o trabalho realizado por ele na primeira recicladora de materiais recicláveis do Brasil. É o testemunho em ato do trabalho etnográfico de 25 anos atrás, assim como de seus desdobramentos atualmente.

Palavras-Chaves: Fotoetnografia - Testemunho - Museu das Memórias (In)Possíveis - Achutti Vila Dique - Memória

Abstract: This article is a testimony of the reunion of Luiz Eduardo Robinson Achutti, and his photographs, with the Vila Dique. It is also a testimony to Achutti's meeting with the Museum of (In)Possibles Memories, which sought out the photographer to precisely make the musealization of his work in the first recyclable materials recycler in Brazil. It is the testimony in action of the ethnographic work of 25 years ago, as well as its developments today.

Key-Words: Photoethnography - Testimony - Museum of (In)Possible Memories - Achutti - Vila Dique - Memory

Esse texto é um testemunho. Um testemunho do reencontro de Luiz Eduardo Robinson Achutti e de suas fotografias com a Vila Dique. É também um testemunho do encontro de Achutti com o Museu das

\footnotetext{
${ }^{1}$ Mestra em Educação (UFRGS), Psicóloga, Psicanalista (APPOA), Idealizadora e Coordenadora do Museu das Memórias (In)Possíveis, Orcid Id: https://orcid.org/0000-0003-1610-3066 E-mail: mairarieck@gmail.com.

${ }^{2}$ Mestra em Memória Social e Patrimônio Cultural (UFPel), Museóloga no Museu das Memórias (In)Possíveis, integrante do Grupo de Pesquisa: "MUSEOLOGIA LAB: Laboratório de Pesquisa em Cultura digital e Museologia Virtual”, endereço dgp.cnpq.br/dgp/espelhogrupo/4350690474743024. Orcid Id: http://orcid.org/0000-0002-2203-6026, E-mail: priscila.museo@gmail.com.
} 
Memórias (In) Possíveis ${ }^{3}$, que procurou o fotógrafo para justamente musealizar o trabalho realizado por ele na primeira recicladora de materiais recicláveis do Brasil, em Porto Alegre, Rio Grande do Sul.

Conhecemos o Achutti no Museu das Memórias (In)Possíveis. Estávamos trabalhando em cima da sua narrativa visual da Vila Dique, das fotografias que ele tirara há mais de 20 anos. Não sabíamos ainda como trabalharíamos com suas fotografias, com sua narrativa etnográfica através delas, nem como abordaríamos o seu conceito inovador de fotoetnografia. Sabíamos que faríamos um trabalho a partir do seu trabalho na Vila Dique. Mas ainda não sabíamos como.

Antes de continuarmos esse testemunho, talvez seja importante dizer o que é afinal de contas o Museu das Memórias (In)Possíveis. Esse Museu é uma invenção que ocupa as bordas da psicanálise e as bordas da museologia. Trata-se de um museu atravessado pelas questões contemporâneas da memória social, um museu virtual que constantemente se atualiza, que está em constante transformação (MAGALDI; BRULON, SANCHES, 2018), um museu atual que potencialmente virtualiza e musealiza memórias, impedindo o seu esquecimento da memória coletiva. É, portanto, um museu de memória, de memórias difíceis, traumáticas e subterrâneas (POLLAK, 1989). É antes de tudo um museu fundado na ética da psicanálise, que busca questionar a forma como construímos o espaço público, as relações humanas. Questionamos para tentar transformar. É um museu de resistência a tudo o que for destruidor de singularidades, de diferenças. Um museu que resiste pela persistência da memória a todas as formas de barbárie e totalitarismo. É, portanto, um Museu-Intervenção (RIECK, 2021).

Figura 1 - Exposição Quando um livro se torna álbum de família (em construção no Museu das Memórias (In)Possíveis).

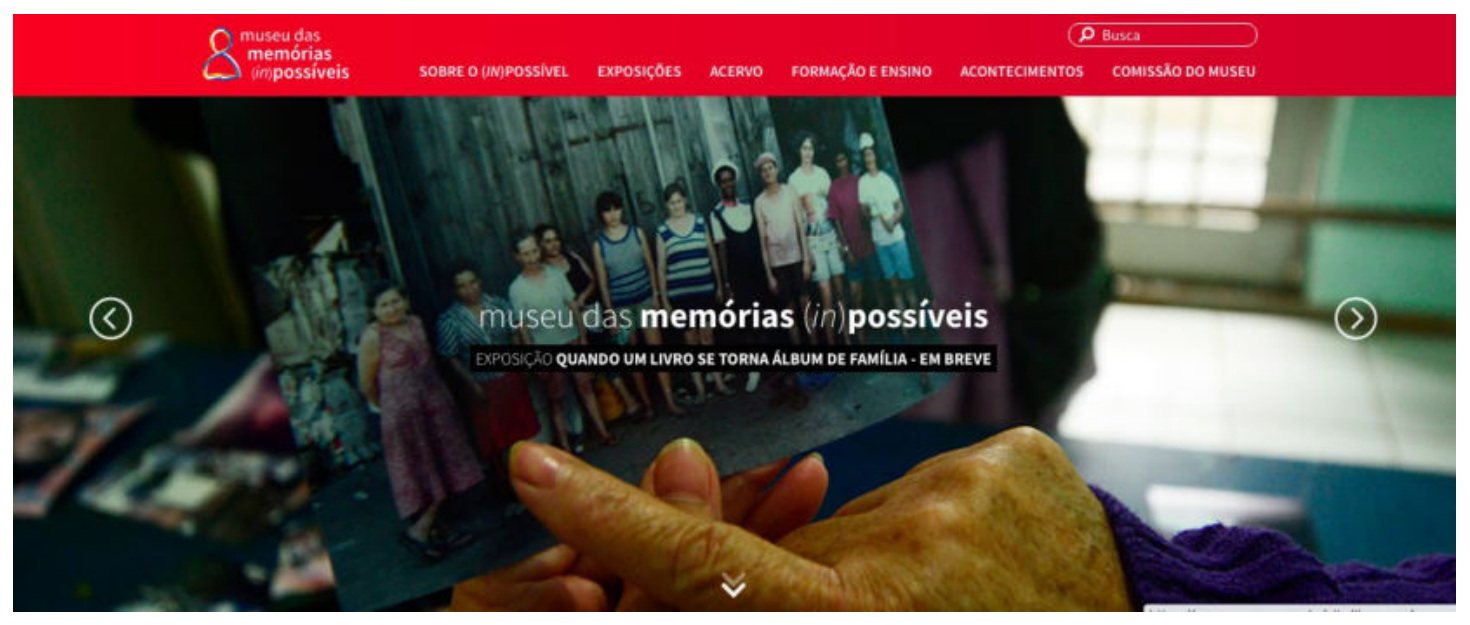

\footnotetext{
${ }^{3}$ Museu das Memórias (In)Possíveis. Disponível em : https://museu.appoa.org.br/site/. Acesso em : 30 mai. 2021.
} 
Fonte: https://museu.appoa.org.br/site/

O trabalho que Achutti desenvolveu na Vila Dique chamou muito a nossa atenção, tanto pela sensibilidade quanto pela potência do que se vê narrado pelas imagens. Seu texto fotoetnográfico trabalha com nosso estoque de experiências visuais propondo outros ângulos ante a realidade do outro, e para nós, suas fotografias dignificavam as pessoas que trabalhavam com o lixo, que muitas vezes em nossa sociedade, acabam sendo tratadas como se lixo fossem. Achutti não seguiu a onda. Suas imagens ressituam o observador e reumanizam os que nunca deveriam ter sido desumanizados. Mais que isso, nos seus encontros com a Vila Dique, Achutti devolveu seu próprio olhar para as trabalhadoras, que eram constantemente presenteadas com suas fotografias, como parte de sua restituição a essa comunidade, tão prezada por Achutti. São muitas as fotos dentro de fotos de Achutti: assim que as presenteava, ele já as fotografava vendo as fotos recebidas, e assim se criava mais uma narrativa da foto dentro da foto dentro da foto. Aos poucos, as mulheres e crianças acostumaram-se com aquela presença na Vila, com as lentes que registravam e narravam suas vidas e trabalhos, e assim, todas essas fotografias passaram a compor também o espaço íntimo das pessoas retratadas.

Figura 2 - A Vila

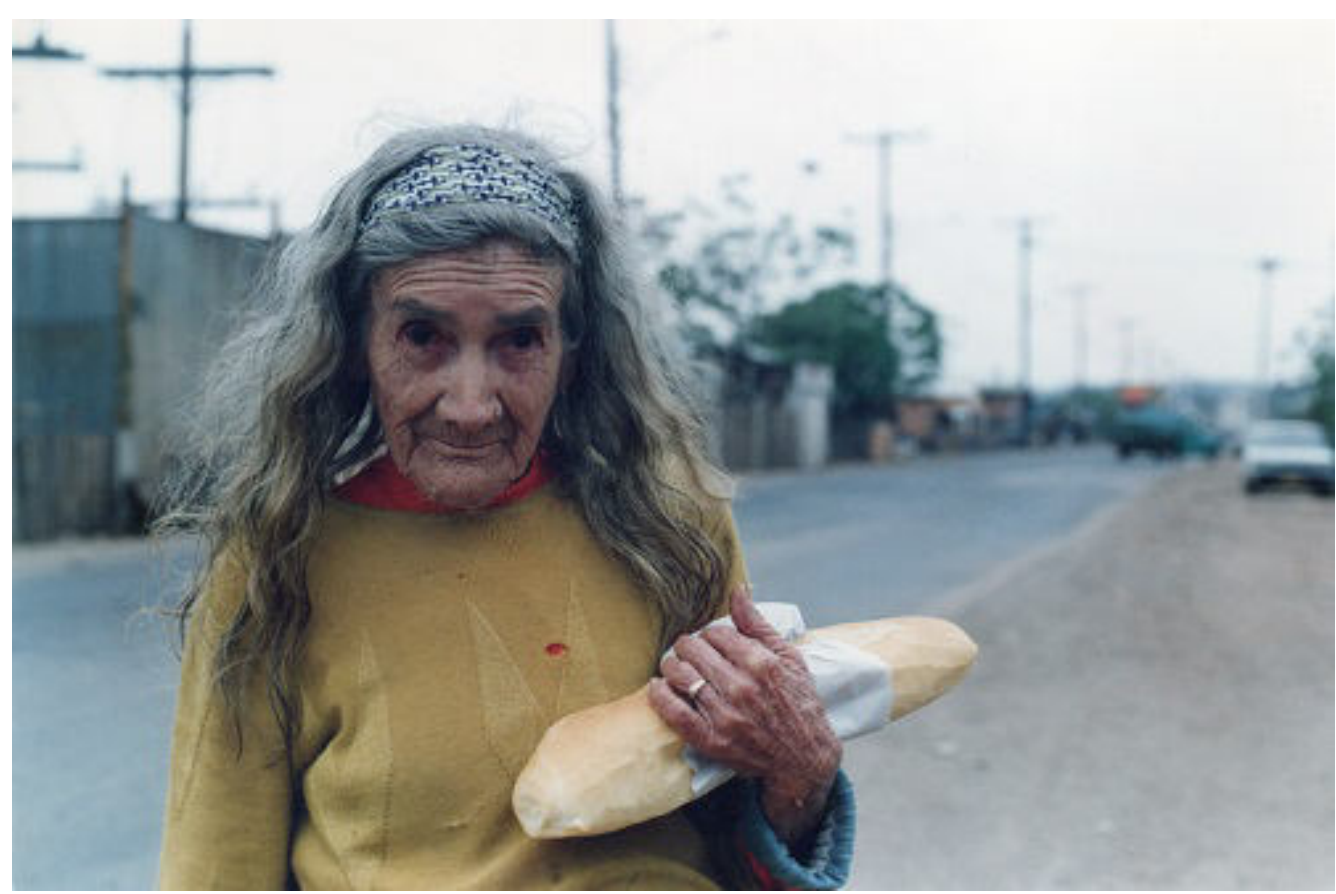


Fonte: Achutti, 1997. Acervo Museu das Memórias (In)Possíveis

Figura 3 - Imagem dentro da Imagem [foto dentro da foto]

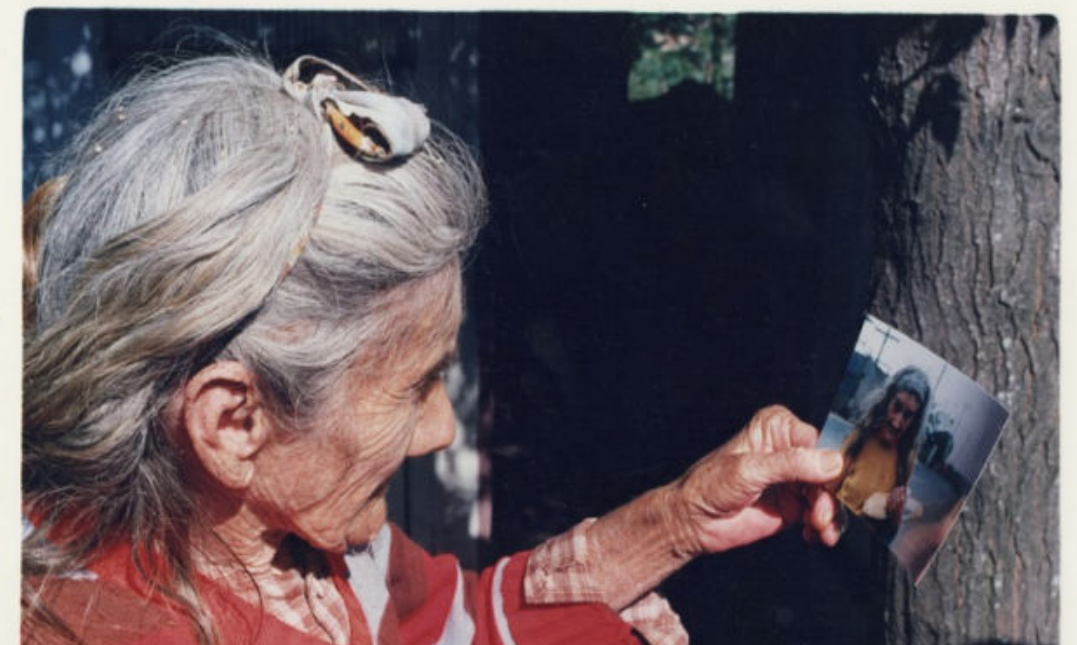


Fonte: Achutti, 1997. Acervo Museu das Memórias (In)Possíveis

Achutti sempre foi muito generoso com o Museu. Com simplicidade, sem desconfiança, nos encontrou por meses para conversarmos, para descobrirmos juntos como montar sua coleção no nosso Museu. Munido de centenas de fotografias, de seus negativos, de seus livros, chegava com suas caixas e pastas aos nossos encontros. Nos entregava os originais para digitalizarmos sem nunca questionar sobre $o$ destino do material. Nos comovia tamanha confiança, mas aumentava ainda mais a nossa responsabilidade de estarmos aptos a receber esse tesouro de imagens, algumas delas nunca publicadas. Recebemos, escaneamos, lhe devolvemos todo o material impresso, mas também o digitalizado - essa seria a restituição do Museu a ele. Mas o que fazer com todo esse material? Como fazer a curadoria dessas fotografias? Que outra narrativa faríamos com elas?

Foi então que Achutti nos contou de Diênnifer. Diênnifer era uma moça que havia entrado em contato com Achutti alguns anos atrás com uma frase enigmática: "Você tem a minha história". A moça tinha sido fotografada por Achutti quando era um bebê de colo e ainda morava com seus pais na Vila Dique. Muitos familiares de Diênnifer tinham sido trabalhadores da recicladora, e a dissertação de Achutti para Diênnifer era uma espécie de álbum de família. Um álbum de família que nunca tivera na infância. Naquela época, não existiam celulares com câmeras; as câmeras fotográficas não eram tão acessíveis, e as fotografias 
tinham que ser reveladas. Algo caro e raro, principalmente no contexto da Vila Dique. As fotos que Achutti presenteava as trabalhadoras eram as fotos que aquelas pessoas tinham. Eram únicas, eram verdadeiros tesouros, eram as suas histórias, eram o suporte das suas memórias.

Figura 4 - [Diênnifer com um ano e seus pais]

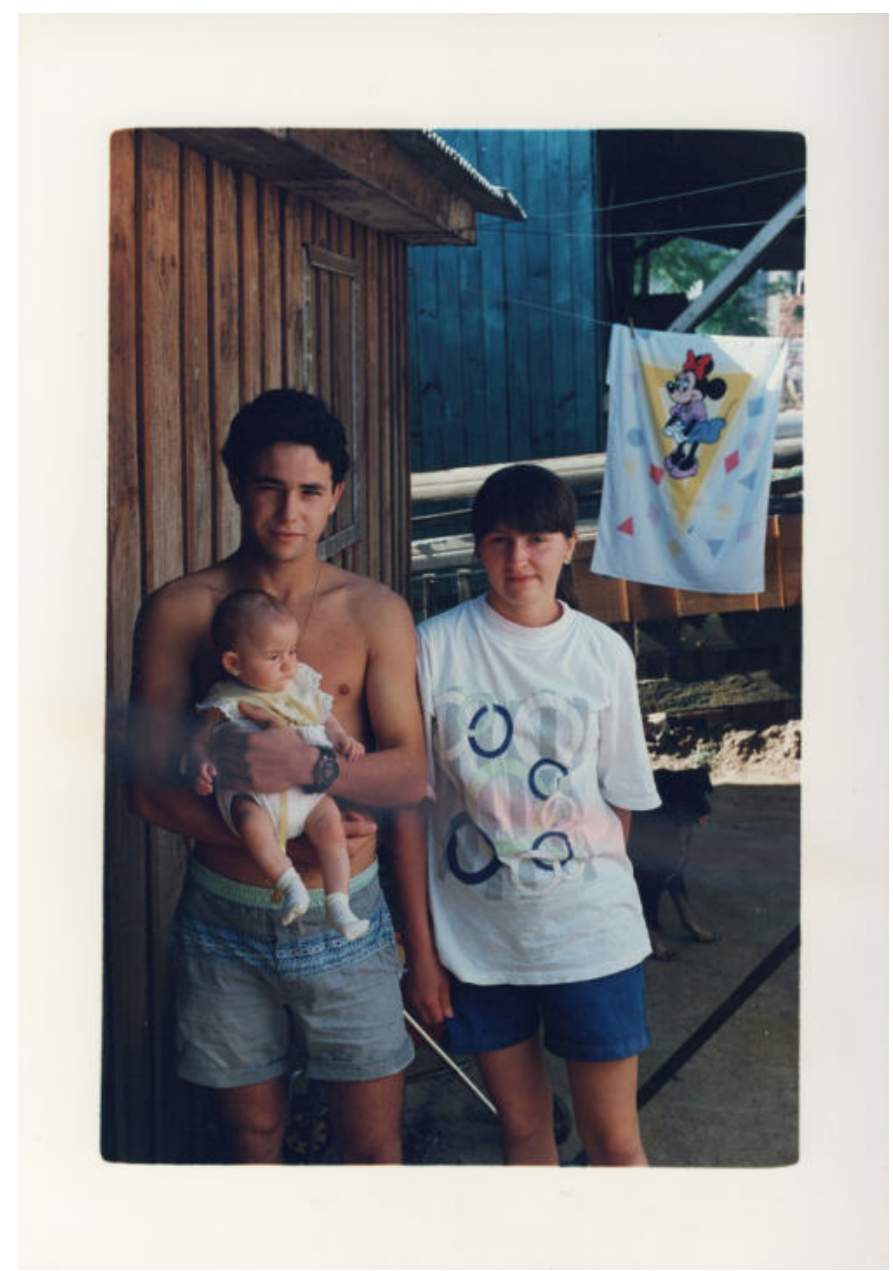


Fonte: Achutti, 1997. Acervo Museu das Memórias (In)Possíveis

Figura 5 - Imagem dentro da Imagem [Diêniffer e a mãe]

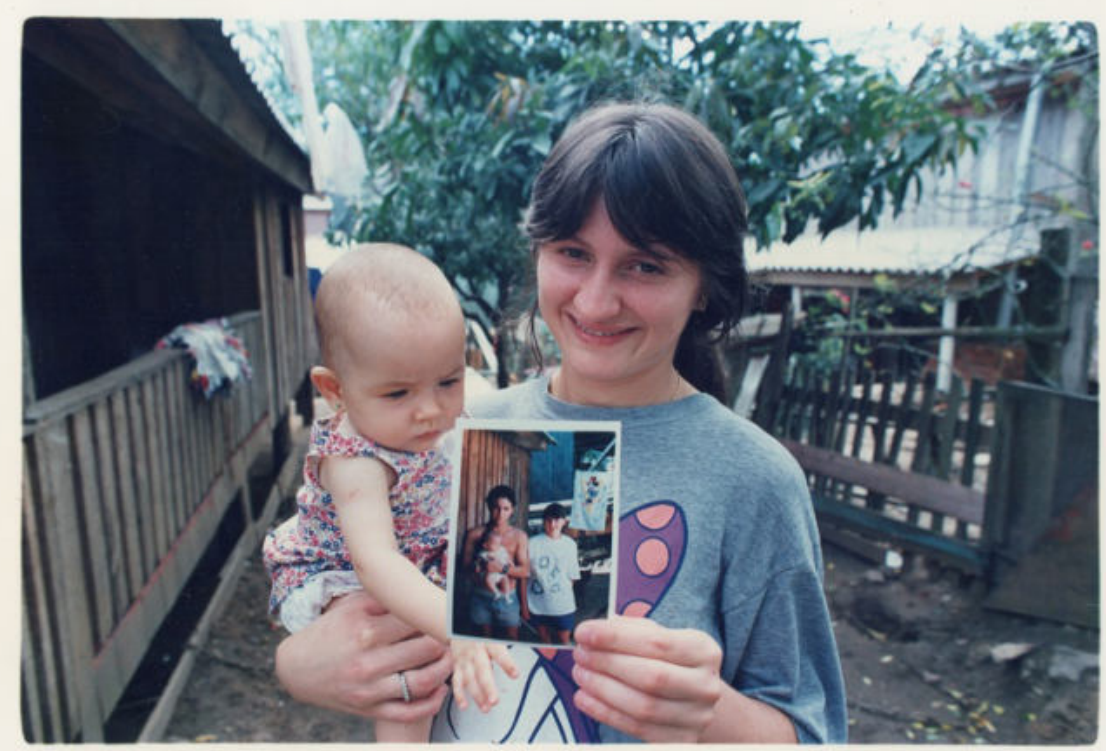


Fonte: Achutti, 1997. Acervo Museu das Memórias (In)Possíveis

Achutti narrou a Vila Dique através de suas fotografias, contou uma história com suas fotos, registrou um marco histórico na cidade de Porto Alegre/RS/Brasil. O que ele não sabia era que ele também estava contando uma história particular, a história de uma família, e que sua dissertação era o álbum de infância de Diênnifer. O seu trabalho acadêmico atingira uma outra dimensão que muito ultrapassou a Universidade. Afetou de maneira sensível a vivência e a experiência das trabalhadoras, que por muitos anos ainda continuaram a sentir a ressonância de seu trabalho - também sentida por Diênnifer.

Não tínhamos mais dúvidas por onde seguiríamos. Passados 4 anos da primeira mensagem de Diênnifer, Achutti - através da intervenção do Museu - marcou um encontro com a moça e sua família. O Museu foi junto para registrar.

Figura 6 - A Vila [A avô de Diêniffer] 


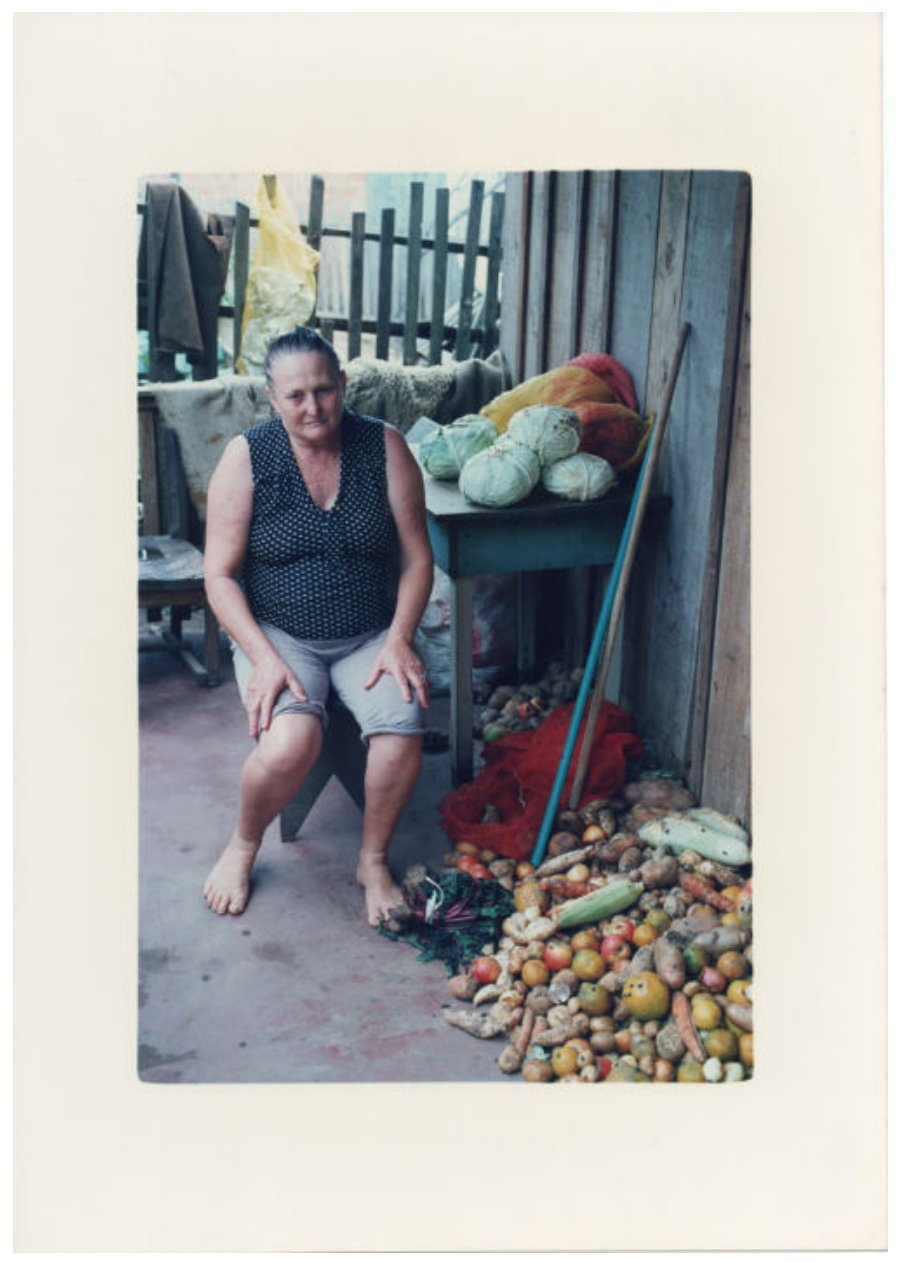

Fonte: Achutti, 1997. Acervo Museu das Memórias (In)Possíveis 
Figura 7 - [Diênnifer mostrando a foto da avó no livro de Achutti.]

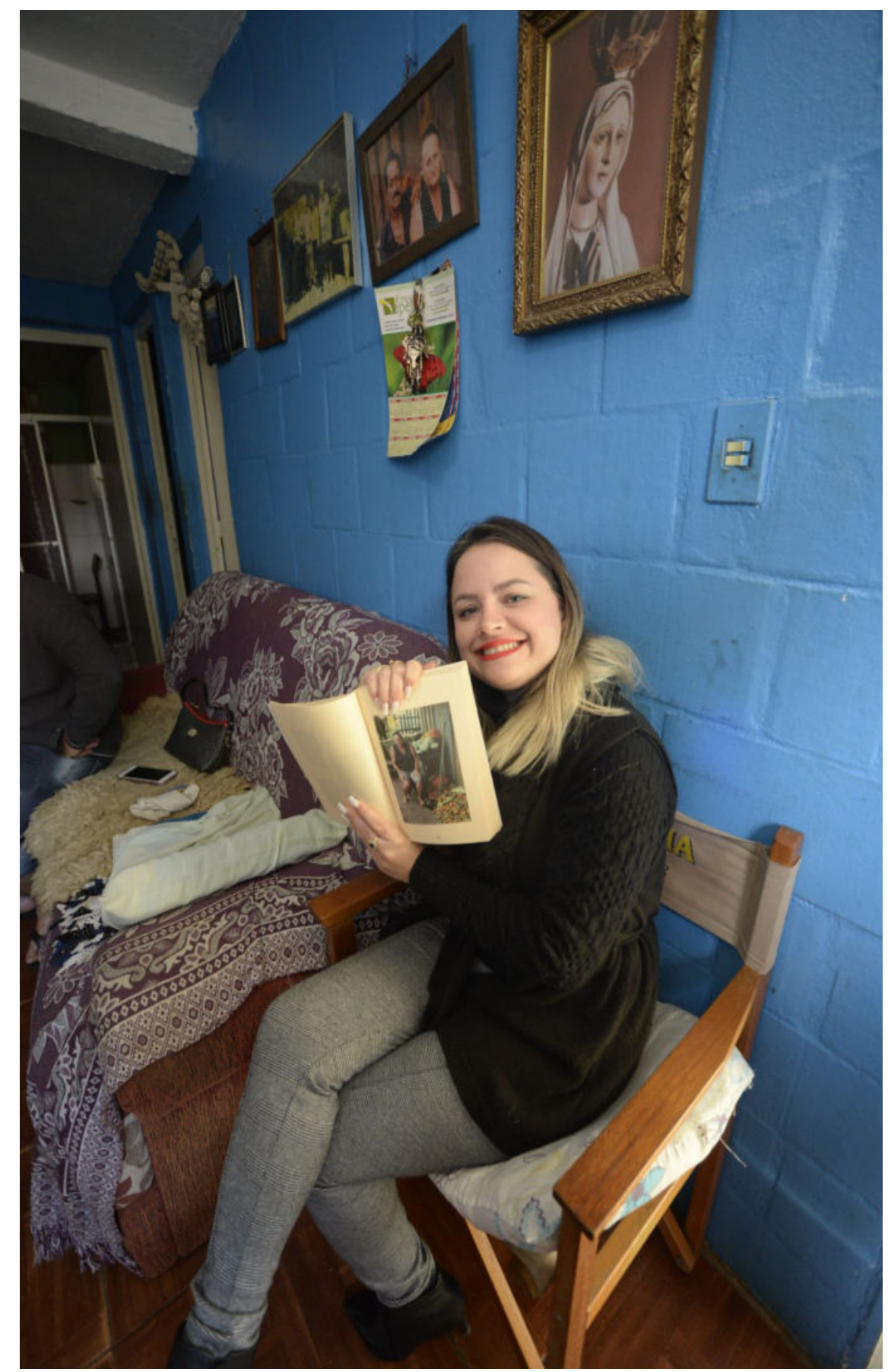


Foto: Achutti, 2019. Acervo Museu das Memórias (In)Possíveis

Fomos duas vezes até a nova Vila Dique ${ }^{4}$ com Achutti, e desses encontros saiu um minidocumentário ${ }^{5}$ realizado pelo Museu das Memórias (In) Possíveis que conta desse retorno do fotógrafo à Vila.

Nesse encontro, Achutti continuou o seu trabalho na mesma ética que sempre teve: continuou contando a história da Vila em imagens. Fotografou adultos segurando suas fotos de criança, fotografou Diênnifer segurando sua foto de bebê. Presenteou os fotografados com fotos antigas, tirou novas fotos. Um trabalho vivo, que nunca foi esquecido pela Vila Dique, nem por Achutti - fotógrafo/etnógrafo e, por que não, um trabalhador da memória.

\footnotetext{
${ }^{4}$ A Vila Dique fotografada por Achutti foi removida para o que se chama informalmente de Nova Vila Dique.

${ }^{5}$ MUSEU das Memórias (In)Possíveis. Luiz Eduardo Achutti - Vila Dique. Youtube, 2021. Disponível em : https://www.youtube.com/watch?v=4w rsa4Y 5Y. Acesso em 30 mai. 2021.
} 
Figura 8 - [Adalton e Alessandra]. 


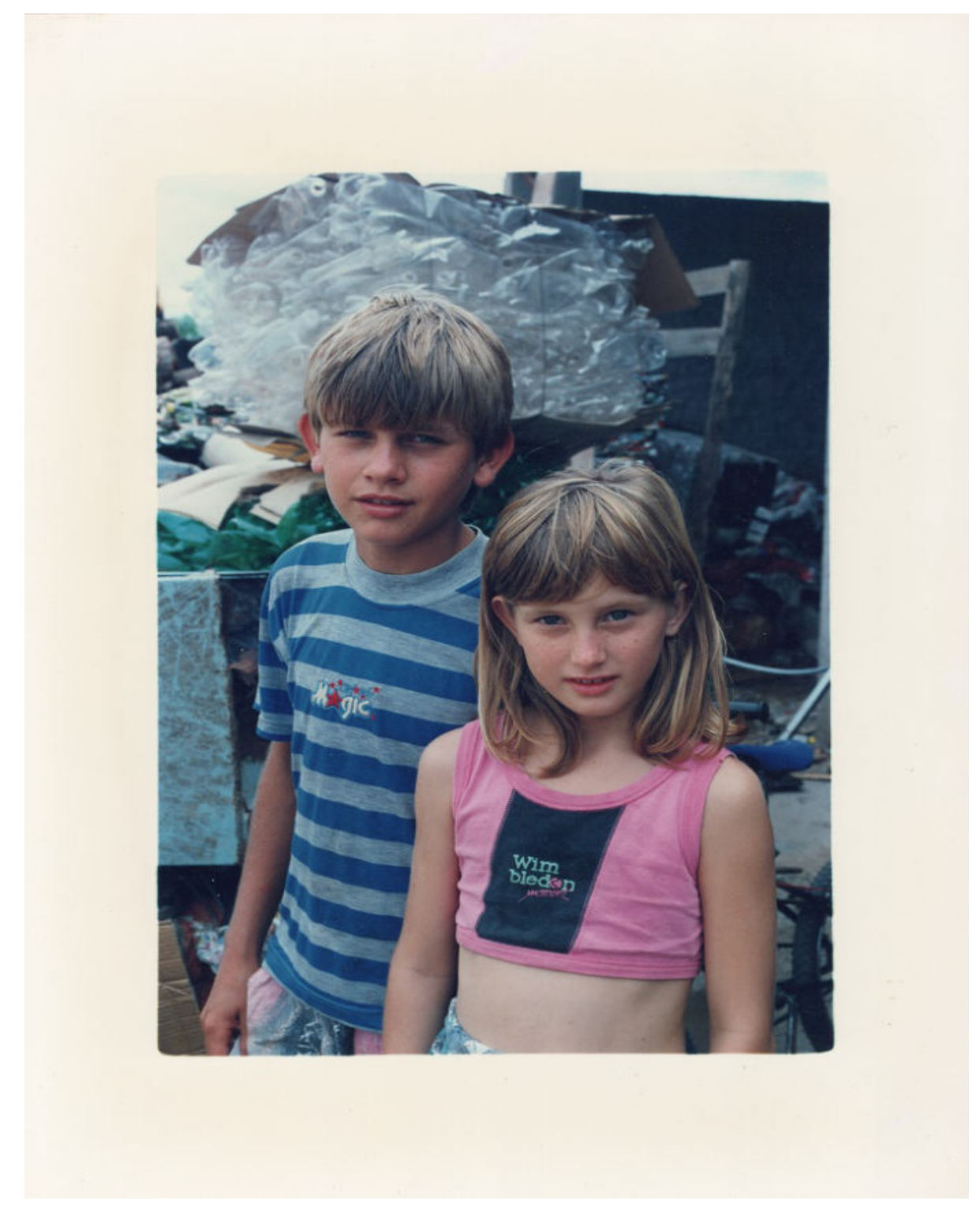

Fonte: Achutti, 1997. Acervo Museu das Memórias (In)Possíveis 
Figura 9 - [Adalton e Alessandra]

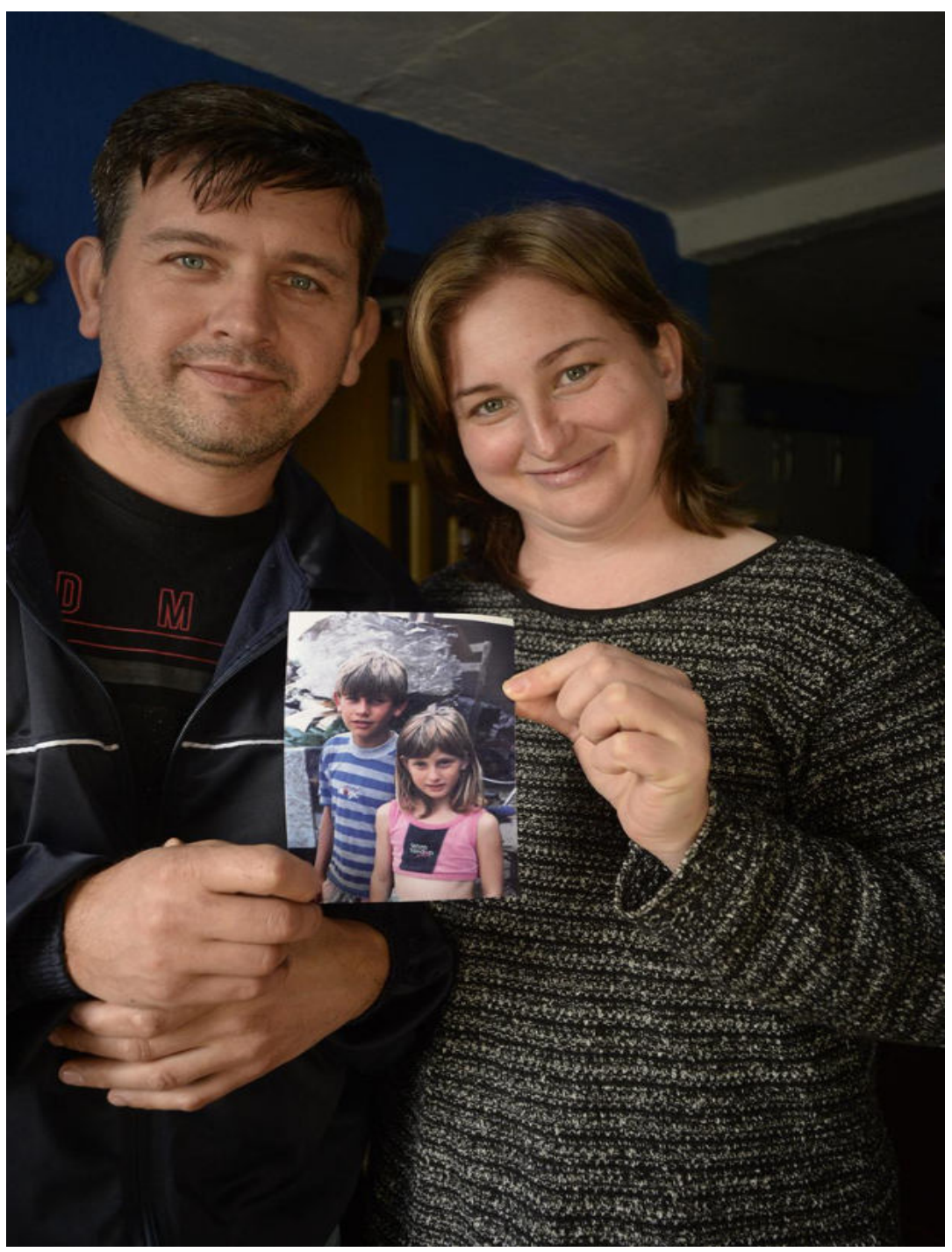

Fonte: Achutti, 2019. Acervo Museu das Memórias (In)Possíveis 
Figura 10 - [Adalton e Alessandra. Foto dentro da foto dentro da foto] 


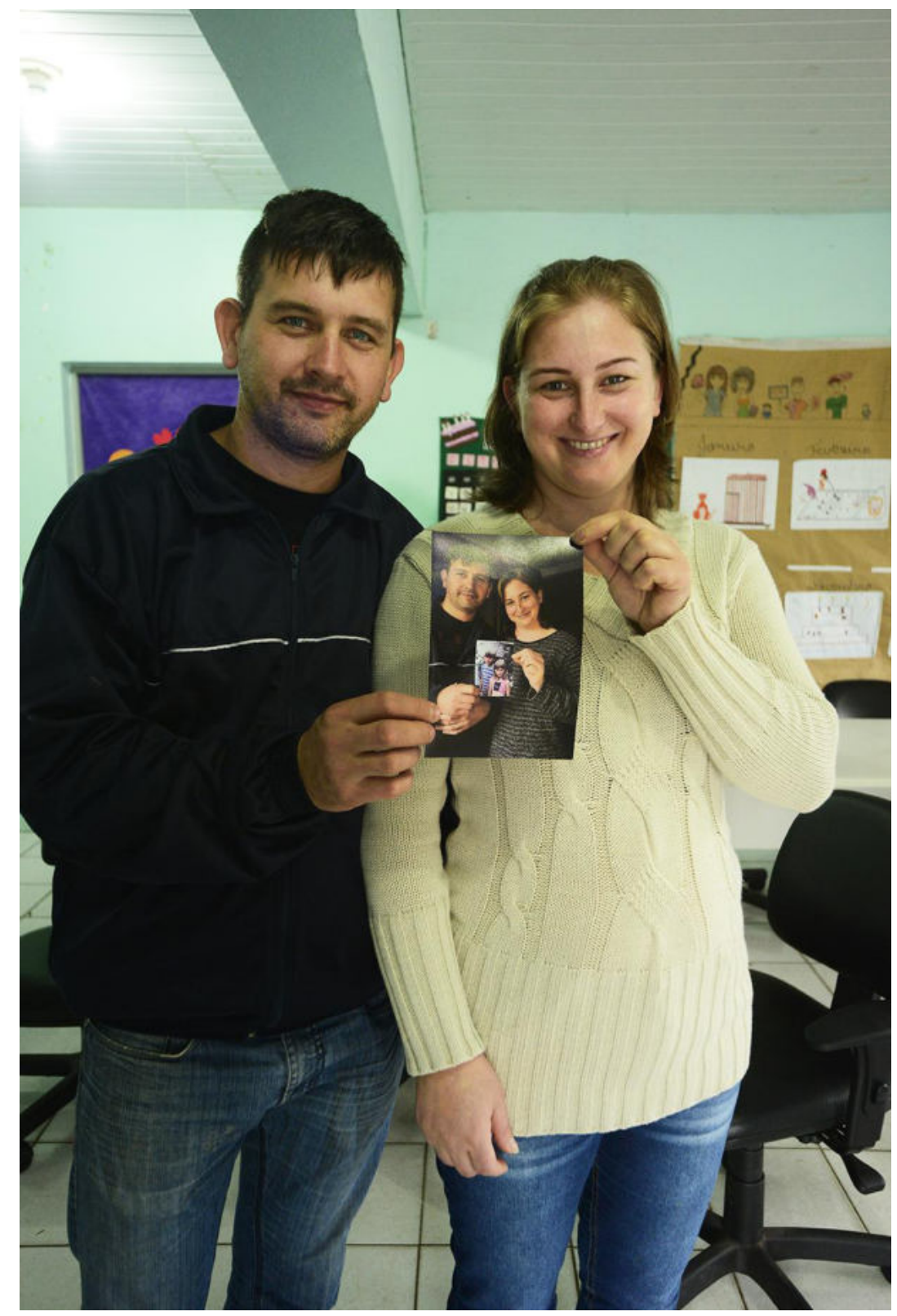

Fonte: Achutti, 2019. Acervo Museu das Memórias (In)Possíveis

Quando Achutti chegou na Vila pela primeira vez, no contexto de sua dissertação de mestrado, foi recebido com desconfiança pelas trabalhadoras da recicladora. Nada mais justo, uma vez que elas estavam cansadas de serem retratadas pela imprensa como lixo, como pobres, como descartáveis. "Não somos lixo, somos trabalhadoras de material reciclável", avisou uma delas. Achutti garantiu a elas que esse não seria o seu olhar. Garantiu e cumpriu. A prova disso veio mais de 20 anos depois com Diênnifer e, depois, no reencontro de Achutti com alguns de seus interlocutores na Vila Dique. Ao Museu, coube escutar Achutti e fazê-lo escutar o apelo de Diênnifer. Coube a nós contar essas histórias de redignificação humana. 
Figura 11 - [Os avós de Diênnifer]

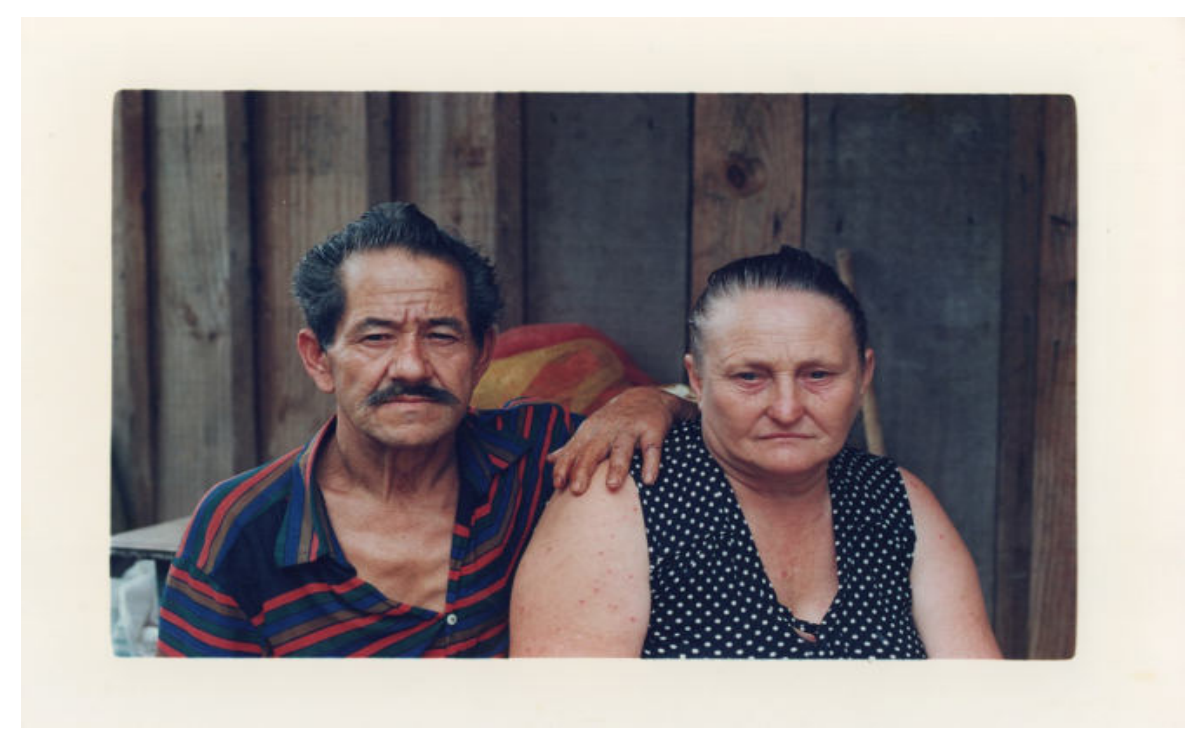

Fonte: Achutti, 1997. Acervo Museu das Memórias (In)Possíveis 
Figura 12 - [Ofrazio Pinheiro, avô de Diênnifer, e a fotografia de Achutti na parede]

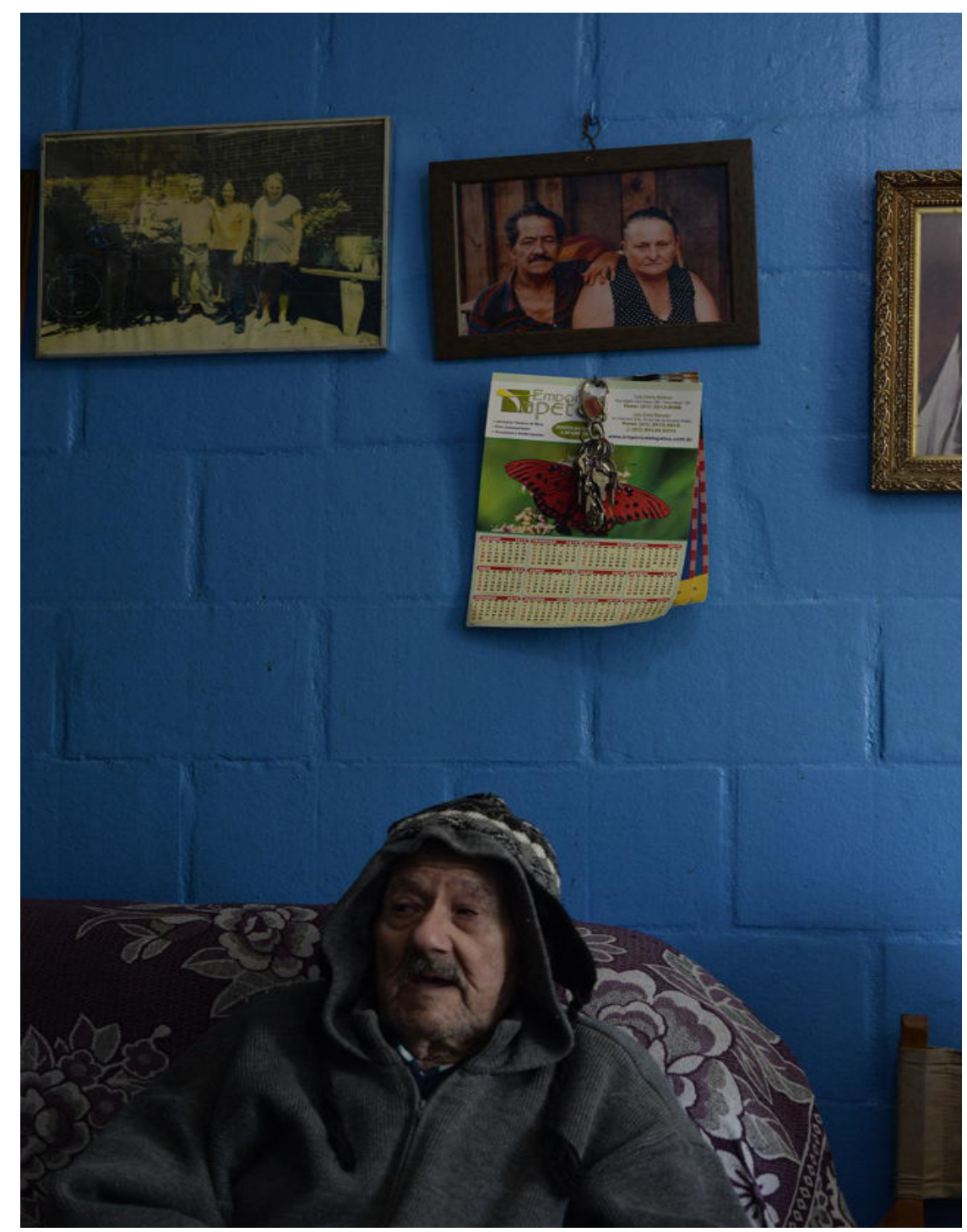

Fonte: Achutti, 2019. Acervo Museu das Memórias (In)Possíveis 
Figura 13 - [Achutti e Ofrazio Pinheiro] 


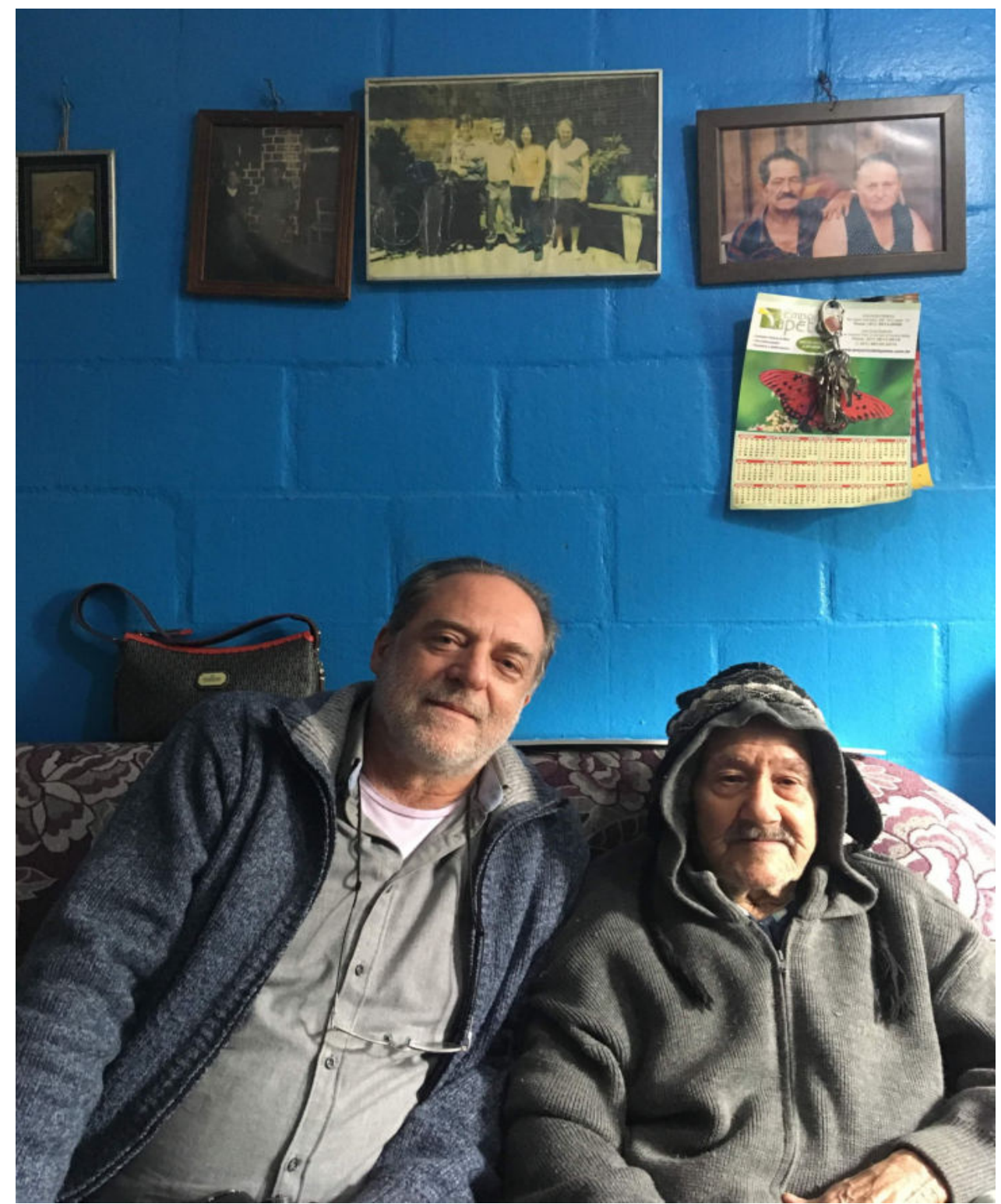

Foto: Maíra Brum Rieck, 2019. Acervo Museu das Memórias (In)Possíveis 


\section{Referências}

ACHUTTI, L.E.R. Fotoetnografia: um estudo de antropologia visual sobre cotidiano, lixo e trabalho. Porto Alegre: Tomo Editorial; Palmarinca, 1997.

MAGALDI, M. B.; BRULON, B.; SANCHES, M.. Cibermuseologia: as diferentes definições de museus eletrônicos e a sua relação com o virtual. In: MAGALDI, Monique BRITO, Clóvis Carvalho (Org.). Museus \& Museologia: desafios de um campo interdisciplinar. Brasília: FCIUnB, 2018. p. 135-155. Disponível em: https://repositorio.unb.br/handle/10482/33198. Acesso em 17/09/2021.

MUSEU das Memórias (In)Possíveis. Coleção Achutti-Vila Dique. 2019. Disponível em: https://museu.appoa.org.br/site/. Acesso em 18/09/2021.

MUSEU das Memórias (In)Possíveis. Luiz Eduardo Achutti - Vila Dique. Youtube, 2021. Disponível em : https://www.youtube.com/watch?v=4w rsa4Y 5Y. Acesso em 30/05/2021.

POLLAK, M.. Memória, Esquecimento, Silêncio... Estudos Históricos, Rio de Janeiro, v. 2, n. 3, p. 3-15, 1989. Disponível em: http://www.uel.br/cch/cdph/arqtxt/Memoria esquecimento silencio.pdf. Acesso em 20/03/2017.

RIECK, M.B. Museu das Memórias (In)Possíveis. Coluna da APPOA. Sul 21. Porto Alegre, 29/06/2021. Disponível em: https://sul21.com.br/opiniao/2021/06/coluna-da-appoa-museudas-memorias-inpossiveis/. Acesso em 17/09/2021. 